\title{
Functional analysis of Paracoccidioides brasiliensis 14-3-3 adhesin expressed in Saccharomyces cerevisiae
}

\author{
Patricia Akemi Assato', Julhiany de Fátima da Silva ${ }^{1}$, Haroldo Cesar de Oliveira ${ }^{1}$, Caroline Maria Marcos ${ }^{1}$, \\ Danuza Rossi ${ }^{2}$, Sandro Roberto Valentini ${ }^{2}$, Maria José Soares Mendes-Giannini ${ }^{1}$, Cleslei Fernando Zanelli ${ }^{2}$ \\ and Ana Marisa Fusco-Almeida ${ }^{{ }^{*}}$
}

\begin{abstract}
Background: 14-3-3 proteins comprise a family of eukaryotic multifunctional proteins involved in several cellular processes. The Pb14-3-3 of Paracoccidioides brasiliensis seems to play an important role in the Paracoccidioides-host interaction. Paracoccidioides brasiliensis is an etiological agent of paracoccidioidomycosis, which is a systemic mycosis that is endemic in Latin America. In the initial steps of the infection, Paracoccidioides spp. synthetizes adhesins that allow it to adhere and invade host cells. Therefore, the aim of this work was to perform a functional analysis of Pb14-3-3 using Saccharomyces cerevisiae as a model.

Results: The functional analysis of Pb14-3-3 was performed in S. cerevisiae, and it was found that Pb14-3-3 partially complemented S. cerevisiae proteins Bmh1p and Bmh2p, which are recognized as two yeast 14-3-3 homologues. When we evaluated the adhesion profile of S. cerevisiae transformants, Pb14-3-3 acted as an adhesin in S. cerevisiae; however, Bmh1p did not show this function. The influence of Pb14-3-3 in S. cerevisiae ergosterol pathway was also evaluated and our results showed that Pb14-3-3 up-regulates genes involved in ergosterol biosynthesis.

Conclusions: Our data showed that Pb14-3-3 was able to partially complement Bmh1p and Bmh2p proteins in S. cerevisiae; however, we suggest that Pb14-3-3 has a differential role as an adhesin. In addition, Pb-14-3-3 may be involved in Paracoccidioides spp. ergosterol biosynthesis which makes it an interest as a therapeutic target.
\end{abstract}

Keywords: Paracoccidioides brasiliensis, 14-3-3 protein, Adhesion, Adhesin

\section{Background}

Paracoccidioides brasiliensis and Paracoccidioides lutzii are the etiological agents of paracoccidioidomycosis, an endemic, systemic mycosis in Latin America, with the highest prevalence in Brazil ( $80 \%$ of cases), where the Southeast and South regions report most of the cases $[1,2]$. It is the eighth highest cause of death among infectious and parasitic diseases and has the highest mortality rate, up to $59 \%$, between systemic mycosis in Brazil in endemic areas [3-5].

The infection occurs through the inhalation of conidia of the mycelial form. Once inside the host, the fungus undergoes a transition to the yeast form, also known as

\footnotetext{
*Correspondence: ana.marisa@uol.com.br

'Laboratório de Micologia Clínica - Núcleo de Proteômica - Faculdade de Ciências Farmacêuticas- Unesp - Campus Araraquara, Rodovia Araraquara Jaú Km 1, 14801-902 Araraquara, SP, Brazil

Full list of author information is available at the end of the article
}

the parasitic form, via temperature stimulation [6]. However, the establishment of the infection depends on several factors, such as the host immune system, the ability of the fungus to evade it and establish itself in the hostile environment provided by the host. In this way Paracoccidioides spp. synthesize several substances that may cause damage in the host cells and assist in colonization [7-10].

An important feature in the host-pathogen interaction is the adhesion process, which contributes to pathogen colonization, dissemination and evasion of the host immune system [11, 12]. Several adhesins that allow the fungus to bind the host extracellular matrix (ECM) have already been described for Paracoccidioides spp. [9]. Among these, 14-3-3 protein plays an important role in Paracoccidioides-host interaction. 
The 14-3-3 protein from $P$. brasiliensis, termed Pb143-3, belongs to the 14-3-3 protein family, and it is composed of approximately $30 \mathrm{kDa}$ acidic dimeric proteins that have already been described in all eukaryotes and are involved in many cellular processes [13-18].

The Pb14-3-3 protein was first described as an adhesin and a laminin ligand [19] and it was identified in P. brasiliensis extracellular vesicles [20]. Da Silva et al. [21] demonstrated using in vitro and in vivo models that during infection, an accumulation of this protein occurred in the fungal cell wall. Additionally, the recombinant protein promoted a decrease in the adhesion rate of $P$. brasiliensis to epithelial cells.

In a study conducted by de Oliveira et al. [22] the expression of adhesins genes and adhesion profile of both $P$. brasiliensis and P. lutzii were compared during interaction with mice and they observed that in both species Pb14-3-3 gene is up-regulated, showing that this protein plays an important role in the host-pathogen interaction in both Paracoccidioides species.

Recently, da Silva et al. [23] evaluated the pneumocytes response when treated with gp43 and Pb14-3-3. The cells exhibited the same profile of apoptosis signaling observed during $P$. brasiliensis infection, highlighting the importance of this protein during the interaction with the host.

Saccharomyces cerevisiae has two encoding genes, $B M H 1$ and $B M H 2$, for 14-3-3 proteins (Bmh1p and Bmh2p) that are involved in innumerable processes, such as sporulation, ergosterol metabolism-related gene transcription and chitin synthesis [14, 24-28].

Although advances in the genetic manipulation of $P$. brasiliensis have been made, Saccharomyces cerevisiae is still extensively used for genetic studies, including functional analyses, due its ease of use and the wide range of available information. [29-34] Thus, we chose this yeast as our model to evaluate the role of the Pb14-3-3 and its relationship with the pathogenicity of $P$. brasiliensis.

\section{Results}

Primary sequence alignment of 14-3-3 proteins

As previously described, S. cerevisiae has two 14-3-3 isoforms, Bmh1p [GenBank: DAA07840.1] and Bmh2p [GenBank: DAA11946.1] [35]. Therefore, using the ClustalW2 amino acid sequence, an analysis was performed between them and Pb14-3-3 [GenBank: AAR24348.1], and a high identity was found among these proteins: Bmh1p and Pb14-3-3 presented an identity of $76 \%$, and Bmh2p and Pb14-3-3 presented an identity of $80 \%$ (Fig. 1).

\section{Molecular cloning of $\mathrm{Pb} 14-3-3$ gene and $\mathrm{BMH} 1$}

The heterologous expression of Pb14-3-3 in S. cerevisiae was carried out using $P$. brasiliensis cDNA to amplify the Pb14-3-3 ORF [GenBank: AY462124] (Fig. 2a), followed by cloning into pYES2 vector. As a control, these procedures were performed using BMH1 ORF [GenBank: X66206.1] because it is the predominantly expressed isoform in S. cerevisiae [35]. After cloning confirmation (Fig. 2b) and sequence analysis, the obtained plasmids, pYES-14-3-3 and pYES-BMH1, and the empty plasmid, pYES, were transformed into wild type (wt), $\Delta b m h 1$ and $\Delta b m h 2 S$. cerevisiae strains using the lithium acetate method for yeast transformation. The positive transformants were selected on SD-URA (synthetic defined medium without uracil) plates.

\section{Complementation assay}

To evaluate the ability of Pb14-3-3 to complement Bmh1p or Bmh2p function in the $\Delta b m h 1$ and $\Delta b m h 2 S$. cerevisiae mutants or to improve the functions of these proteins in the $w t S$. cerevisiae, we performed a spot test using fluconazole (FZ) $35 \mu \mathrm{M}$ as described in the Materials and Methods. The Pb14-3-3 promoted a decrease in fluconazole susceptibility, and a higher complementation was observed in the $\Delta b m h 2 S$. cerevisiae mutant, probably due to the higher identity of Pb14-3-3 with Bmh2p from S. cerevisiae (Fig. 3).

In addition, as fluconazole acts in ergosterol biosynthesis, there is evidence that Pb14-3-3 may be involved in ergosterol biosynthesis, as found with $S$. cerevisiae Bmh1/2 proteins $[26,36]$.

\section{Expression analysis of genes related to ergosterol pathway}

In order to test our hypothesis, we evaluated the expression of genes involved in ergosterol pathway by Real Time PCR. Bmh1p and Bmh2p influence in ergosterol pathway have already been described and downregulation of ERG1, ERG11, ERG28 and HES1 genes were observed in $S$. cerevisiae $B M H 1 / 2$ mutants [26]. In this sense, those genes were chosen to evaluate the possible role of Pb14-3-3 in ergosterol pathway.

An increase of expression of all evaluated genes was observed in the three $S$. cerevisiae transformants containing pYES-BMH1 and pYES-14-3-3 when compared to the S. cerevisiae pYES.transformants (Fig. 4). The expression analysis showed an increased expression of all genes in the $w t$ and $\Delta b m h 1$ S. cerevisiae containing pYES-14-3-3 when compared to the pYES-BMH1 transformants, with a significant increase for ERG1, ERG28 and HES1. In $\triangle b m h 2$ S. cerevisiae transformed with pYES-14-3-3 a slight increase is observed for ERG28 and HES1 genes. These data demonstrate that $\mathrm{Pb} 14-3-3$ is also involved in ergosterol pathway by altering the expression of these genes.

In addition, it seems like Bmh1p has a higher influence in this pathway, once ERG1, ERG11, ERG28 and HES1 showed a higher expression in $\triangle b m h 2 S$. cerevisiae containing pYES-BMH1, which have the $B M H 1$ gene and the plasmid, than $\Delta b m h 1 S$. cerevisiae, which expression of Bmh1p occurs only through the plasmid. 


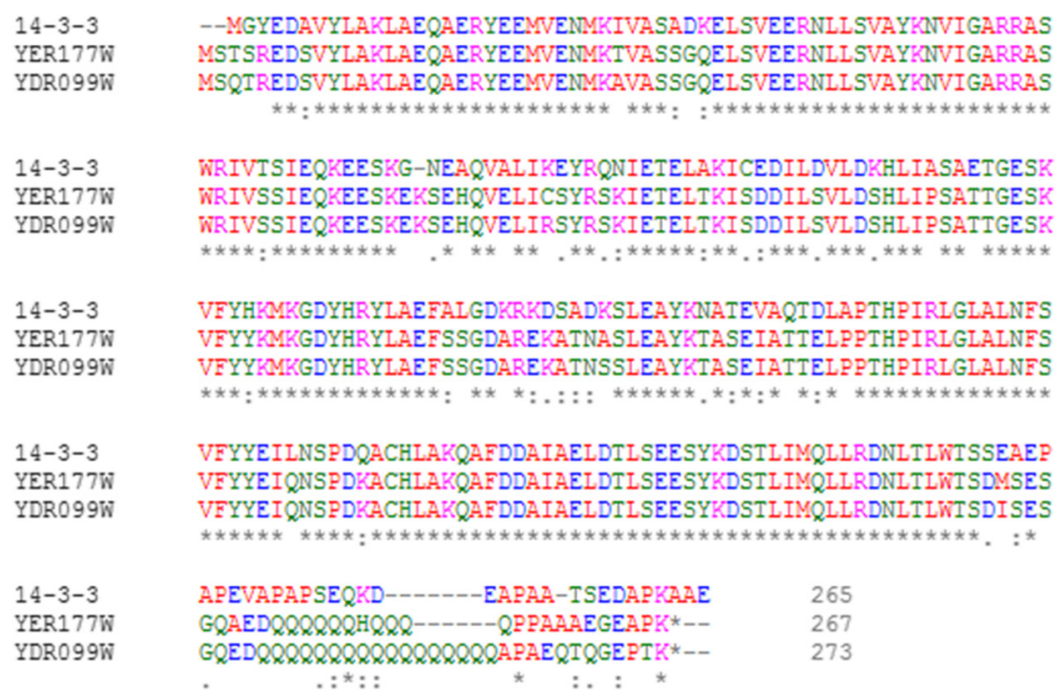

Fig. 1 Primary sequence analysis. An "*" (asterisk) indicates positions that have a single, fully conserved residue; A ":" (colon) indicates conservation between groups with strongly similar properties - scoring > 0.5 in the Gonnet PAM 250 matrix; A "." (period) indicates conservation between groups of weakly similar properties - scoring $=<0.5$ in the Gonnet PAM 250 matrix. The code of colors according to their physicochemical properties are as follows: red, small and hydrophobic (AVFPMILW); blue, acidic (DE); magenta, basic (RK); and green, (STYHCNGQ)

\section{Adhesion assay}

Pb14-3-3 was identified in our group as an adhesin, hence, we performed an adhesion assay to evaluate the ability of Pb14-3-3 to induce S. cerevisiae adherence to epithelial cells (ATCC A549).

A significant increase in adhesion was only observed in wt S. cerevisiae transformed with pYES-14-3-3, showing that Pb14-3-3 acts as an adhesin even in a non-pathogenic fungus. However, Bmh1p did not promote the increase of the adhesion rate, suggesting a differential role of Pb14-33 (Fig. 5a).

In $\Delta b m h 1$ and $\Delta b m h 2 S$. cerevisiae transformants with pYES14-3-3 or pYESBMH1 no increase of adhesion rate was observed, although it was unexpected, the $\mathrm{Pb}-14-3$ -
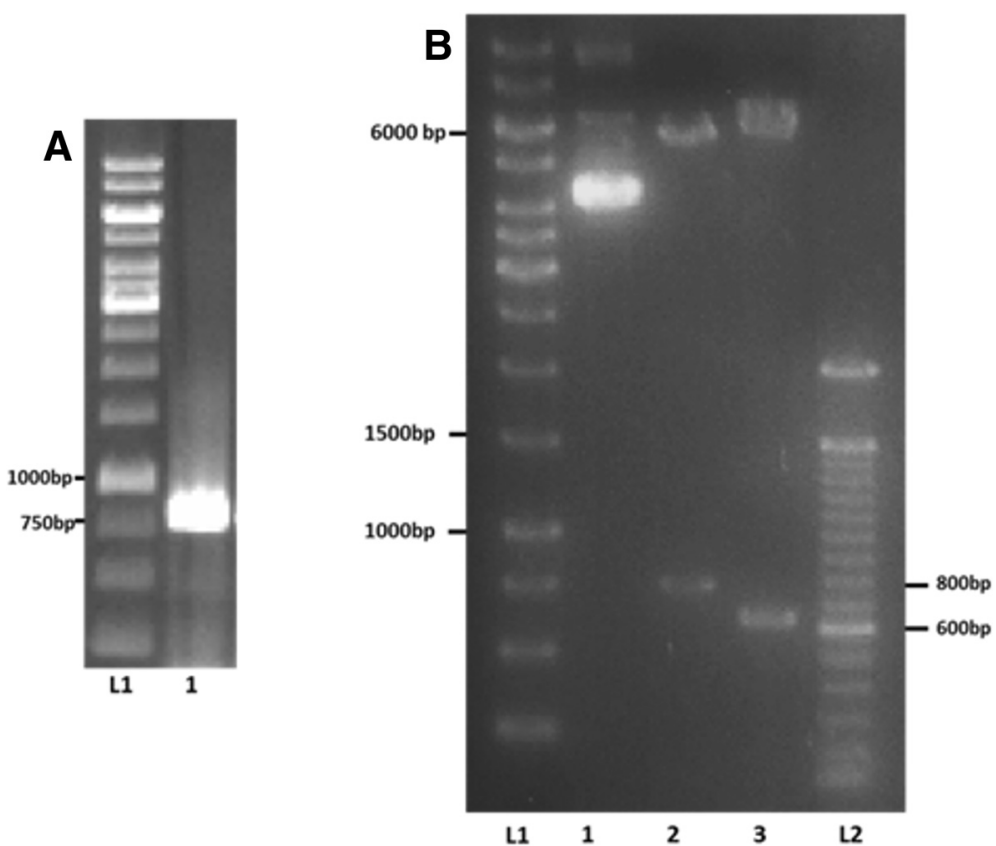

Fig. 2 Agarose gel electrophoresis. a Confirmation of Pb14-3-3 ORF amplification: (L1) 1 kb ladder and (2) Pb14-3-3 ORF (798 bp). b Restriction diagnosis: (L1) 1 kb ladder; 1 - pYES-14-3-3, (2) restriction products using BamH1 and Xhol (expected product 798 bp), and (3) restriction products using BamHI and HindIII (expected product 605 bp), (L2) 100 bp ladder 

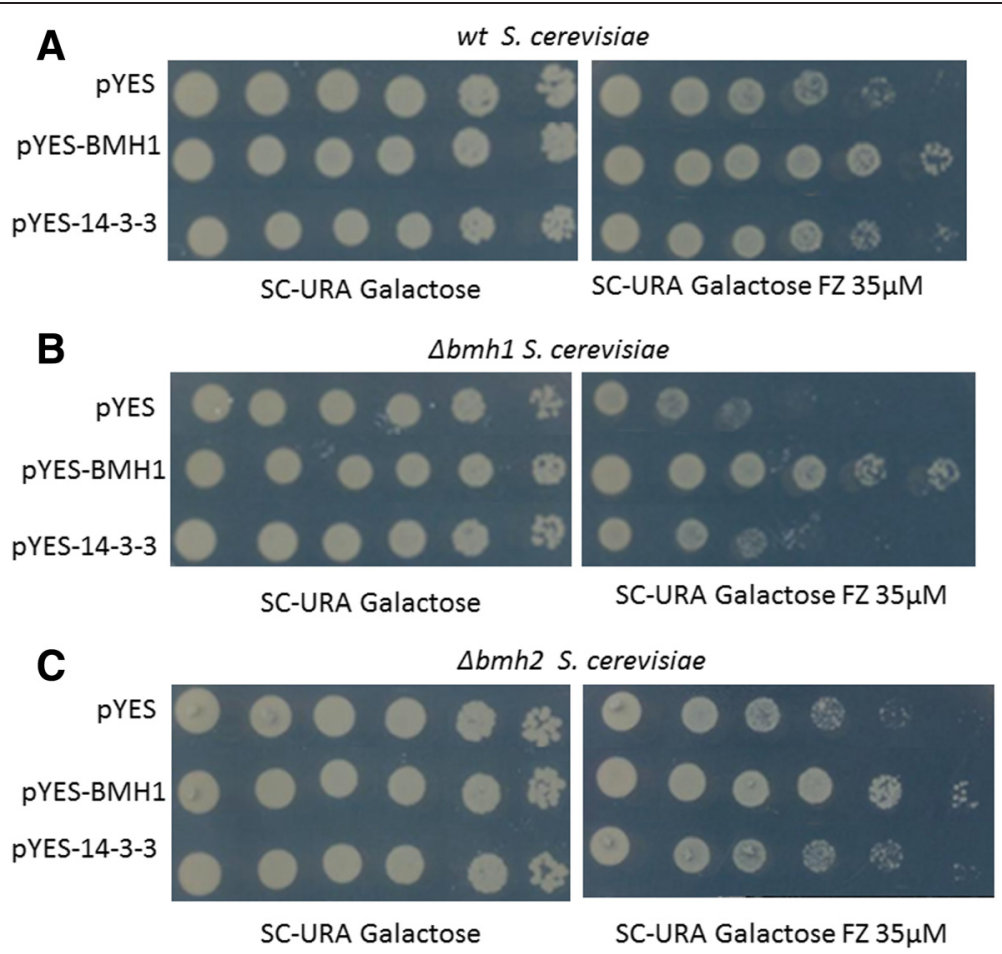

Fig. 3 Evaluation of complementation. A spot assay was used to evaluate susceptibility to fluconazole $35 \mu \mathrm{M}$ in $w t$ (a), $\Delta \mathrm{bmh}$ ( (b) and $\Delta \mathrm{bmh} 2$ (c) S. cerevisiae transformants. There was a decreased sensitivity of transformants pYES-14-3-3 and pYES-BMH1 compared with the empty vector transformant (pYES). As a growth control, the transformants were also spotted in SD-URA without fluconazole

3 may be acting in Bmh1p or Bmh2p primary functions in order to compensate the lack of missing genes, meanwhile wt S. cerevisiae possess both genes and $\mathrm{Pb} 14-3-3$ can be required for secondary functions, as adhesin (Fig. 5).

\section{Discussion}

As with many pathogens, Paracoccidioides spp. adhesion to host cells is a crucial event in the establishment of disease and contributes to the colonization and invasion of host cells, as well as evasion from the host immune system $[9,11,12]$. Therefore, Paracoccidioides adhesins are important proteins to be studied because they might promote a better understanding of fungal pathogenesis and provide new targets for antifungals.

Several Paracoccidioides spp. adhesins have already been described, such as the $43 \mathrm{kDa}$ glycoprotein, gp 43 , which is most studied Paracoccidioides spp. adhesin that

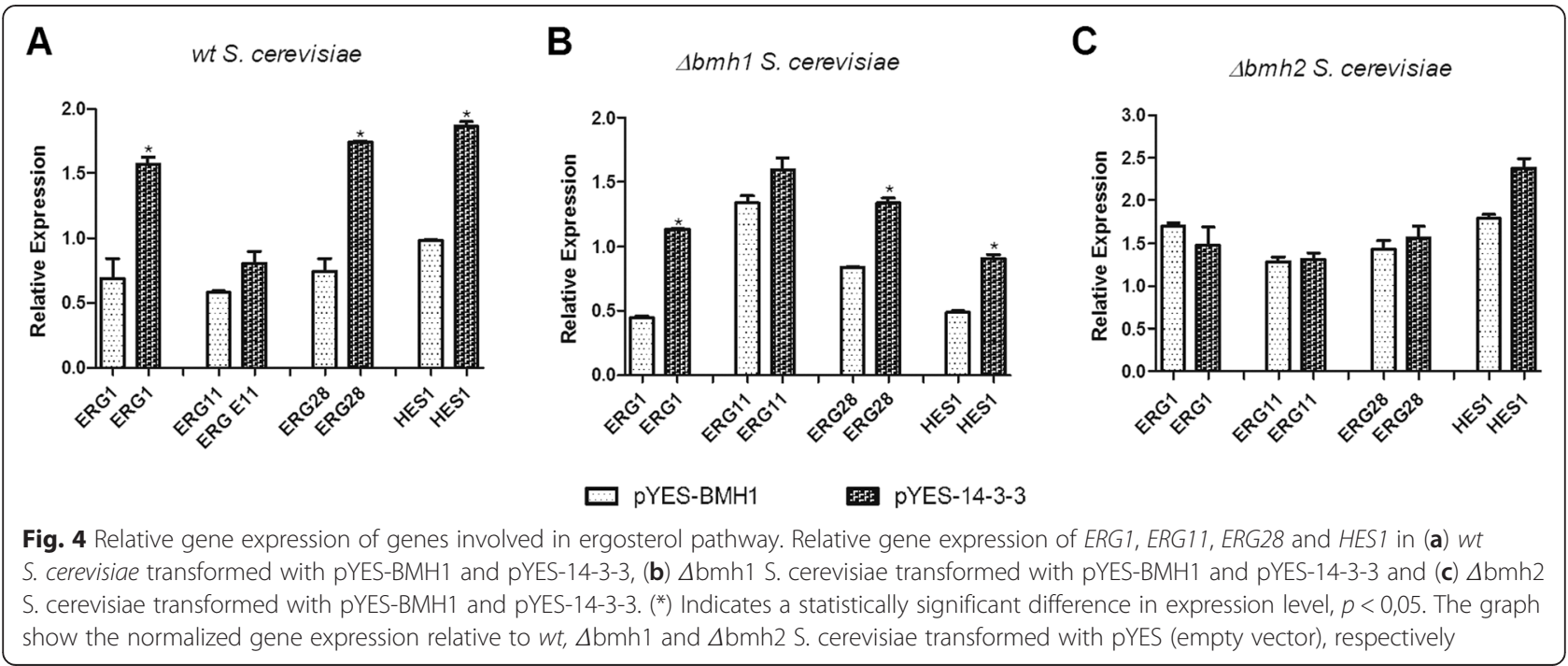




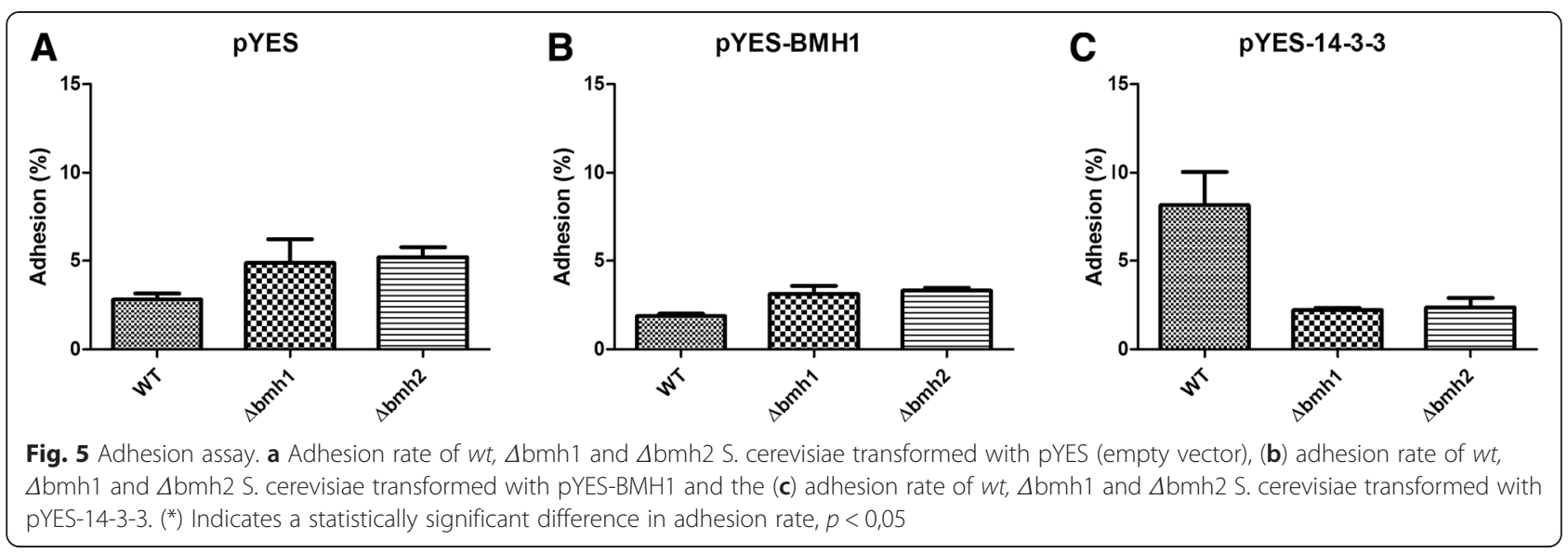

binds to laminin and fibronectin and is also used as a serological marker [37-40]; glyceraldehyde-3-phosphatedehydrogenase $(\mathrm{GAPDH})$, enolase (ENO), triose phosphate isomerase (TPI), malate synthase (MLS), aconitase (ACO) and isocitrate lyase (ICL), which, in addition to their primary roles in the metabolism, are found in the fungal cell wall and are able to bind to different components of the ECM [41-49]; and the $30 \mathrm{kDa}$ protein identified as the 14-3-3 protein, which stands out in Paracoccidioides - host interaction [21].

The 14-3-3 proteins comprise a family of small, dimeric and acidic proteins that are present in all eukaryotic cells $[16,18,50]$. The closest relation between 14-3-3 protein and fungus virulence was first described by Andreotti et al. [19], where they found an increase in the expression of a $30 \mathrm{kDa}$ protein after animal reisolation and that this $30 \mathrm{kDa}$ protein binds to laminin and it is able to inhibit $P$. brasiliensis adhesion and invasion in epithelial cells. Later, da Silva et al. [21] identified this protein as being related to a member of the 14-3-3 protein family and demonstrated that Pb14-3-3 accumulates in the fungal cell wall during infection in both in vitro and in vivo models.

As genetic manipulation of $P$. brasiliensis are still hard to accomplish [51], we decided to use $S$. cerevisiae as a model to improve our knowledge about Pb14-3-3. The double knockout of $B M H 1$ and $B M H 2$ genes are lethal [31], then we decided to evaluate $\mathrm{Pb} 14-3-3$ function in single mutant and wild type strains of $S$. cerevisiae, a strategy successfully used by Clapp et al. [52].

As the first description of Pb14-3-3 was as an adhesin, we performed an adhesion assay to evaluate the ability of $\mathrm{Pb}-14-3-3$ to promote $S$. cerevisiae adhesion to pneumocytes. A significant increase in the adhesion rate was observed for $w t$ S. cerevisiae transformed with pYES-14-3-3, but not with pYES-BMH1 and pYES. However, this was not observed in any transformed $S$. cerevisiae mutants (Fig. 5).

In this way, as $S$. cerevisiae is a non-pathogenic microorganism the adhesion process is not required to the yeast, therefore, when $\Delta b m h 1$ and $\Delta b m h 2 S$. cerevisiae express Pb14-3-3, the protein is recruited to perform the primary functions of the missing gene, $B M H 1$ and $B M H 2$, respectively, as it occurs with the Bmh1p and Bmh2 proteins [35]. However, in the wt S. cerevisiae transformants there is no need to supplement any function and the protein expressed through the plasmid perform secondary function and act as adhesin. Interesting, only wt S. cerevisiae pYES-14-3-3 showed an increase in adhesin rate compared to the $w t S$. cerevisiae pYES suggesting although the high identity, $\mathrm{Pb} 14-3-3$ may present different functions than Bmh1p, such as an adhesin.

Although 14-3-3 proteins are multifunctional proteins that are involved in several cellular processes $[16,18,27$, 28,53 , which may have influenced the adhesion of $S$. cerevisiae, the $\mathrm{Pb} 14-3-3$ role in adhesion process during Paracoccidioides spp. interaction with host cells in vitro and in vivo have already been demonstrated [21]. Additional role of conserved proteins in pathogenic organisms, including Paracoccidioides spp., during interaction with host cells has already been described. Enzymes from glycolytic pathway, tricarboxylic cycle and glyoxylate cycle are found in fungus cell wall during infection and are able to interact with ECM components, assisting in the fungus adherence $[22,49,54]$.

In humans, this protein has been widely study as a target for drug development or as a biomarker [55-57] because it has been associated with neurodegenerative disease, such as Creutzfeldt-Jakob disease, Alzheimer's disease $[17,24,58,59]$ and some cancer types [60, 61] .

However, the knowledge of the influence of 14-3-3 proteins in pathogenic fungi is still limited. Candida albicans encodes a single 14-3-3 gene, BMH1 [62], which the expressed protein is involved in growth and filamentation that may affect the host-fungus interaction [63]. It was also recognized by $C$. albicans germ-tubespecific antibodies in the detection of invasive candidiasis, highlighting the potential as a biomarker for diagnosis [64]. 
The 14-3-3 proteins of some parasites have also been studied in regards their involvement in infectious diseases [65]. In Trypanosoma brucei, 14-3-3 proteins were related to cell motility, cytokinesis and the cell cycle [66, 67]; the 14-3-3 protein from Toxoplasma gondii seems to stimulate the host immune system and is a promising vaccine candidate $[68,69]$. Several studies of $14-3-3$ proteins from the genus Ecchinococcus suggest the importance of this protein in host-parasite interactions, where it can be involved in the regulation of cell proliferation, survival and invasion, as well as in the modulation of the host immune system [70-73]. The same behavior was also verified in 14-3-3 proteins from the genus Schistosoma and studies have been conducted to development of vaccines and diagnostic methods [74-78].

In Aspergillus nidulans, the expression of 14-3-3 protein was also identified and seems to be involved in hyphae morphogenesis as its overexpression promoted defects in the establishment of the germ tube and asexual development [79].

In this study, we also demonstrated that Pb14-3-3 could partially complement the functions of Bmh1p and Bmh2p by decreasing the susceptibility to fluconazole at $35 \mu \mathrm{M}$, showing a greater complementation in the mutant $S$. cerevisiae $\Delta b m h 2$, which was expected because according to the amino acid alignment analysis, we observed a higher identity between Pb14-3-3 and Bmh2p than between Pb14-3-3 and Bmh1p.

In addition, it is well known that in azoles, such as fluconazole, the mechanism of action takes place in ergosterol biosynthesis by interrupting the conversion of lanosterol into 4,4-dimethylcholesta-8,14,24-trienol [80].

Thus, we hypothesized if Pb14-3-3 may be related to ergosterol biosynthesis due to the decreased sensibility of the $S$. cerevisiae strains transformed with pYES-14-33 . To verify that, we performed an expression analysis of genes involved in ergosterol pathway, ERG1, ERG11, ERG28 and HES1, which have already been described to be regulated by Bmh1p and Bmh2p [26].

The Pb14-3-3 promoted the up-regulation of all evaluated genes, demonstrating its involvement in ergosterol pathway in this model. In addition, the upregulation promoted by $\mathrm{Pb} 14-3-3$ was higher than promoted by Bmh1p, this was specially observed for the genes ERG1, ERG28 and HES1 wt and $\triangle b m h 1 S$. cerevisiae transformants.

Ergosterol is the major sterol in fungi and it is an essential structural component of plasma membrane. Also, ergosterol acts in membrane permeability and in membrane-bound enzymes [81, 82]. In pathogenic fungus ergosterol is a microbe associated molecular pattern and because of the differences between ergosterol and human sterols it is widely study in the development of antifungal compounds [83-86].
The currently antifungals used in treatment of paracoccidioidomycosis, itraconazole and amphotericin B, have as target enzymes of ergosterol pathway, such as ERG11p, and ergosterol, respectively [87-91]. The resistance and effect of these antifungals in pathogenic fungi have been studied [92-94], Da Silva Neto et al [82], studied the transcriptional profile of Paracoccidioides treated with itraconazole and observed an up-regulation of genes from ergosterol biosynthesis.

The ergosterol biosynthesis is performed by genes from ERG family. ERG1 and ERG11 genes encode essential enzymes in the initial stages of ergosterol biosynthesis, acting in the conversion of squalene into squalene epoxide and of lanosterol into 4,4-dimethylcholesta-8,14,24-trienol, respectively. ERG28p seems to be a key enzyme in the ergosterol biosynthesis, once interacts with seven ergosterol biosynthetic enzymes, where the association with ERG11p, ERG27p, ERG25p and ERG6p are more closely and with ERG1p and ERG26p are less associated [95]. HES1 is related to ergosterol biosynthesis and sterol transport [96, 97].

The role of Paracoccidioides spp. in adhesion process and this new role here described, in ergosterol biosynthesis, reinforce the importance of this protein in host-pathogen interactions and its potential as therapeutic target.

\section{Conclusion}

These findings corroborate results presented in previous studies. Here, we demonstrated that Pb14-3-3 acts as an adhesin, even in a non-pathogenic model. This protein has adhesin function unlike Bmh1p, despite the high identity between these proteins.

The influence of Pb14-3-3 in ergosterol pathway was also demonstrated in this model and we believe that also happens in Paracoccidioides spp.. Further studies should be conducted in order to evaluate this new function of Pb14-3-3 and its implications in Paracoccidioides spp. pathogenesis and virulence. However, this highlights the importance of this protein and its potential as therapeutic target against Paracoccidioides spp..

\section{Methods}

\section{Microorganisms and growth conditions}

In this study, $P$. brasiliensis $\mathrm{Pb} 18$ strain in the yeast phase was cultured in Fava Netto medium at $37{ }^{\circ} \mathrm{C}$ and was used to perform RNA extraction.

S. cerevisiae wild type (wt), $\Delta b m h 1$ (bmh1::KanMX4) and $\Delta b m h 2$ (bmh2::KanMX4) strains were generously provided by Dr. Cleslei Fernando Zanelli from the Molecular Biology Laboratory of Faculty of Pharmaceutical Sciences. They were maintained in YEPD (yeast extract peptone dextrose) medium at $25{ }^{\circ} \mathrm{C}$. After transformation, the yeast cells were maintained in the selective medium SD-URA. 
The Escherichia coli DH10B strain was employed for plasmid amplification and was maintained in LuriaBertani (LB) medium. After transformation, the positive transformants were selected in LB supplemented with ampicillin $(50 \mu \mathrm{g} / \mathrm{mL})$.

\section{Cloning of the Paracoccidioides brasiliensis 14-3-3 gene into pYES expression vector}

Genomic DNA from $S$. cerevisiae strains were obtained through the phenol: chloroform: isoamilic alcohol method according to Hanna and Xiao [98], whereas the $P$. brasiliensis RNA extraction was performed by the TRIzol method (Invitrogen Life Technologies, Carlsbad, CA, USA) according to the manufacturer's instructions followed by cDNA synthesis using reverse transcriptase (RevertAid ${ }^{\mathrm{TM}} \mathrm{H}$ Minus Reverse Transcriptase, Fermentas, Canada) and $1 \mu \mathrm{g}$ of total RNA.

Amplification of Pb14-3-3 [GenBank: AY462124] and Bmh1p [GenBank: X66206.1] coding regions were carried out through PCR using the specific primers 14-3-3 F/14$3-3 \mathrm{R}$ and BMH1F/BMH2R (Table 1). The PCR products were checked by agarose electrophoresis, purified using a QIAquick PCR Purification kit (Qiagen, Redwood City, CA, USA) and quantified using a NanoVue Plus (GE Healthcare Buckinghamshire, UK).

The 14-3-3 amplicon was cloned into BamHI/XhoI sites of the pYES2 vector expression system (Invitrogen Life Technologies, Carlsbad, CA, USA), and the Bmh1 amplicon was cloned into BamHI/EcoRI sites of the pYES2 vector expression system (Invitrogen Life Technologies, Carlsbad, CA, USA). The obtained plasmids, pYES-14-3-3 and pYES-BMH1, were transformed into E. coli DH10B through the heat shock method, and then the bacteria was plated in LB medium supplemented with ampicillin $50 \mu \mathrm{g} / \mathrm{mL}$ and incubated overnight at $37^{\circ} \mathrm{C}$.

Positive colonies were grown, and plasmid extraction was performed using QIAprep Spin Miniprep (Qiagen, Redwood City, CA, USA). To ensure that the plasmid extracts were pYES-14-3-3 and pYES-BMH1, restriction diagnosis was performed using HindIII and BamHI enzymes (Promega, Madison, Wi, USA). After confirmation, transformation in yeast was initiated.

The $w t, \Delta b m h 1$ and $\Delta b m h 2 S$. cerevisiae strains were submitted to yeast transformation with pYES-14-3-3 and pYES-BMH1 (used as a complementation control) through the lithium acetate method. After transformation, yeast cells were plated in SD-URA medium to select positive transformants and incubated at $30{ }^{\circ} \mathrm{C}$ until the appearance of growth.

\section{Spot test}

The spot test was performed to evaluate the ability of Pb14-3-3 to complement the functions of Bmh1p or Bmh2p. Fluconazole was chosen after searching the
Table 1 Oligonucleotides used for plasmids construction and Real Time PCR study

\begin{tabular}{ll}
\hline Name & Description (5' $\left.{ }^{\prime}{ }^{\prime}\right)$ \\
\hline $14-3-3 F$ & CGGGATCCATGGGTACGAAGATG \\
14-3-3R & CCGCTCGAGCTACTCAGCGGCCTTAGG \\
BMH1F & CG GGATCC ATGTCAACCAGTCGTGAAG \\
BMH1R & CG GAATTC TTACTITGGTGCTTCACC \\
ERG1F & ATCCATTGACTGGTGGTGGT \\
ERG1R & CGGTCGCTGAAGTCTAGGTC \\
ERG11F & CCTCTTATTCCGTCGGTGAA \\
ERG11R & TGTGTCTACCACCACCGAAA \\
ERG28F & CAACCCATTTGAGTGCAAGA \\
ERG28R & GAAGTGGAATAGGGCAACCA \\
HES1F & TGTGGCAGAAGCAATCAGAC \\
HES1R & CTITGCCATTCCACACCTIT \\
ACT1F & CGGTGATGGTGTACTCACG \\
ACT1R & GGCCAAATCGATTCTCAAAA \\
\hline
\end{tabular}

Saccharomyces Genome Database, where a decrease in sensitivity to fluconazole was described for $S$. cerevisiae $\Delta b m h 1$ and $\Delta b m h 2$.

Each transformant was grown in SD-URA medium until a concentration of $1 \times 10^{7}$ cells $/ \mathrm{mL}\left(\mathrm{A}_{600 \mathrm{~nm}}=0.6-\right.$ $0.9)$, and suspensions of $2.5 \times 10^{8}$ cells $/ \mathrm{mL}$ were prepared in glycerol $50 \%$. Then, $100 \mu \mathrm{L}$ of each sample was transferred to a 96-well plate, six serial dilutions were prepared and $2.5 \mu \mathrm{L}$ of each suspension was spotted in SD-URA supplemented with $2 \%$ galactose and $35 \mu \mathrm{M}$ fluconazole (Sigma-Aldrich, St. Louis, MO, USA); control plates without fluconazole were also made. The plates were incubated at $30{ }^{\circ} \mathrm{C}$ until growth in all dilutions was observed in control plates. The experiment was conducted in triplicate with three independent experiments for each transformant.

\section{Expression analysis of ergosterol pathway genes ERG1, ERG11, ERG28 and HES1 by Real Time PCR}

The evaluated genes, ERG1, ERG11, ERG28 and HES1, were chosen according to Bruckmann et al. [26] and $A C T 1$ was used as housekeeping gene. Specific primers for each gene were synthetized (Table 1).

Saccharomyces cerevisiae transformants were grown in SD-URA medium overnight at $30{ }^{\circ} \mathrm{C} / 150 \mathrm{rpm}$ and then transferred to induction medium, which consisted of SD-URA with $2 \%$ galactose. The cells were collected and RNA extraction was performed by the TRIzol method (Invitrogen Life Technologies, Carlsbad, CA, USA) according to the manufacturer's instructions followed by first-strand cDNA synthesis using reverse transcriptase (RevertAid ${ }^{\mathrm{Tm}} \mathrm{H}$ Minus Reverse Transcriptase, Fermentas, CA) and $1 \mu \mathrm{g}$ of total RNA. 
The reaction mixtures contained $1 \mu \mathrm{L}$ of cDNA, $10 \mu \mathrm{L}$ of Maxima ${ }^{\bullet}$ SYBR Green/ROX qPCR Master Mix (2X) (Fermentas, Canada), $0.7 \mu \mathrm{M}$ of each primer and nuclease-free water to the final volume of $20 \mu \mathrm{L}$ The reactions were performed in Applied Biosystems 7500 Real Time PCR System (Applied Biosystems, Foster City, CA, USA) with the following program: $50{ }^{\circ} \mathrm{C}$ for $2 \mathrm{~min}, 95{ }^{\circ} \mathrm{C}$ for $10 \mathrm{~min}$, and 40 cycles of $95^{\circ} \mathrm{C}$ for $15 \mathrm{~s}$ followed by annealing and synthesis at $60{ }^{\circ} \mathrm{C}$ for $1 \mathrm{~min}$. Following the PCR, a melting curve analysis was performed, which confirmed that the signal corresponded to a single PCR product. The data were analyzed using the $2^{-\Delta \Delta C T}$ method. The cycle threshold values for the triplicate PCRs of each RNA sample were averaged, and then the values were calculated using the ACT1 gene which was chosen as reference housekeeping gene [99].

Before the relative expression analyses, the efficiency of the amplifications were performed, then experiments were conducted in triplicate with three independent experiments for each primer and sample. Statistical analysis was performed using ANOVA test followed by Turkey's post-test. The analyses and the graphs construction were conducted in GraphPad Prism5 software (GraphPad Software Inc., La Jolla, CA, USA).

\section{Adhesion assay}

The adhesion assay was performed according to Younes et al. [100] with some modifications. Saccharomyces cerevisiae transformants were grown in SD-URA medium containing $2 \%$ raffinose overnight at $30{ }^{\circ} \mathrm{C} / 150 \mathrm{rpm}$ and then transferred to induction medium (SD-URA with $2 \%$ galactose) and incubated for 4 hours under the same conditions described above.

In 24-well plates, pneumocytes (ATCC A549) were plated with HAM-F12 medium supplemented with fetal bovine serum and incubated at $36.5{ }^{\circ} \mathrm{C}, 5 \% \mathrm{CO}_{2}$ until monolayer formation. Then, the cells were washed three times, and new medium was added. In each well, $300 \mu \mathrm{L}$ of each inoculum was added to a final concentration of $1 \times 10^{4}$ yeast cells $/ \mathrm{mL}$.

The plates were incubated for $30 \mathrm{~min}$ at $36.5{ }^{\circ} \mathrm{C} / 5 \% \mathrm{CO}_{2}$. After this period, they were washed to remove non adherent yeast cells. The epithelial cells were lysed with $100 \mu \mathrm{L}$ of cold water and plated in YEPD medium incubated for $36 \mathrm{~h} / 30{ }^{\circ} \mathrm{C}$. The colony count was performed, and the adhesion rate was expressed as the percentage of adhered cells in relation to control plates.

The experiments were carried out in triplicate with three independent experiments and statistical analysis was performed using an ANOVA test with a Tukey's post-test. The analyses and the graphs were conducted in GraphPad Prism5 software (GraphPad Software Inc., La Jolla, CA, USA).

\section{Abbreviations}

ACO: aconitase; ATCC: American Type Culture Collection; ECM: extracellular matrix; ENO: enolase; FZ: fluconazole; GAPDH: glyceraldehyde-3-phosphatedehydrogenase; Gp43: 43 kDa glycoprotein; ICL: isocitrate lyase; LB: LuriaBertani; MLS: malate synthase; Pb14-3-3: 14-3-3 protein from Paracoccidioides brasiliensis; PCR: polymerase chain reaction; SD-URA: synthetic defined medium without uracil; TPI: triose phosphate isomerase; wt: wild type; YEPD: yeast extract peptone dextrose.

\section{Competing interests}

The authors declare that they have no competing interests.

\section{Authors' contributions}

PAA, CFZ and AMFA conceived and designed the experiments. PAA, $\mathrm{HCO}, \mathrm{JFS}, \mathrm{CMM}$, and DR performed the experiments. PAA, HCO, JFS, CMM, DR, SRV, CFZ, MJSMG and AMFA analyzed the data. PAA, HCO, JFS, CMM, CFZ and AMFA drafted the manuscript. All authors read and approved the final manuscript.

\section{Acknowledgments}

This work was supported by Brazilian organizations: Fundação de Amparo à Pesquisa do Estado de São Paulo (FAPESP) 2011/18038-9, Coordenação de Aperfeiçoamento Pessoal de Nível Superior (CAPES), Conselho Nacional de Desenvolvimento Científico e Tecnológico (CNPq) 473119/2010-2 and Programa de Apoio ao Desenvolvimento Científico da Faculdade de Ciências Farmacêuticas da UNESP (PADC). We thank Rosângela Aparecida Moraes da Silva for technical support and Mariana Marchi Santoni for technical support with yeast transformation procedures.

\section{Author details}

'Laboratório de Micologia Clínica - Núcleo de Proteômica - Faculdade de Ciências Farmacêuticas- Unesp - Campus Araraquara, Rodovia Araraquara Jaú Km 1, 14801-902 Araraquara, SP, Brazil. 'Laboratório de Biologia Molecular - Faculdade de Ciências Farmacêuticas- Unesp - Campus Araraquara, Rodovia Araraquara - Jaú Km 1, 14801-902 Araraquara, SP, Brazil.

Received: 22 April 2015 Accepted: 23 October 2015

Published online: 04 November 2015

\section{References}

1. Mendes-Giannini MJ, Hanna SA, da Silva JL, Andreotti PF, Vincenzi LR, Benard G, et al. Invasion of epithelial mammalian cells by Paracoccidioides brasiliensis leads to cytoskeletal rearrangement and apoptosis of the host cell. Microbes Infect. 2004;6(10):882-91.

2. Ameen M, Talhari C, Talhari S. Advances in paracoccidioidomycosis. Clin Exp Dermatol. 2010;35(6):576-80.

3. Coutinho ZF, Silva D, Lazera M, Petri V, Oliveira RM, Sabroza PC, et al. Paracoccidioidomycosis mortality in Brazil (1980-1995). Cad Saude Publica. 2002;18(5):1441-54.

4. Santo AH. Paracoccidioidomycosis-related mortality trend, state of São Paulo, Brazil: a study using multiple causes of death. Rev Panam Salud Publica. 2008;23(5):313-24.

5. Prado M, Silva MB, Laurenti R, Travassos LR, Taborda CP. Mortality due to systemic mycoses as a primary cause of death or in association with AIDS in Brazil: a review from 1996 to 2006. Mem Inst Oswaldo Cruz. 2009;104(3):513-21.

6. McEwen JG, Bedoya V, Patiño MM, Salazar ME, Restrepo A. Experimental murine paracoccidiodomycosis induced by the inhalation of conidia. J Med Vet Mycol. 1987;25(3):165-75.

7. Goldman GH, dos Reis ME, Duarte Ribeiro DC, de Souza Bernardes LA, Quiapin AC, Vitorelli PM, et al. Expressed sequence tag analysis of the human pathogen Paracoccidioides brasiliensis yeast phase: identification of putative homologues of Candida albicans virulence and pathogenicity genes. Eukaryot Cell. 2003;2(1):34-48.

8. Rappleye CA, Goldman WE. Defining virulence genes in the dimorphic fungi. Annu Rev Microbiol. 2006;60:281-303.

9. Mendes-Giannini MJ, Andreotti PF, Vincenzi LR, da Silva JL, Lenzi HL, Benard G, et al. Binding of extracellular matrix proteins to Paracoccidioides brasiliensis. Microbes Infect. 2006;8(6):1550-9.

10. Horn F, Heinekamp T, Kniemeyer O, Pollmächer J, Valiante V, Brakhage AA. Systems biology of fungal infection. Front Microbiol. 2012;3:108. 
11. Govender VS, Ramsugit S, Pillay M. Mycobacterium tuberculosis adhesins: potential biomarkers as anti-tuberculosis therapeutic and diagnostic targets. Microbiology. 2014;160(Pt 9):1821-31.

12. Ribet $D$, Cossart $P$. How bacterial pathogens colonize their hosts and invade deeper tissues. Microbes Infect. 2015;17(3):173.

13. Gelperin D, Weigle J, Nelson K, Roseboom P, Irie K, Matsumoto K, et al. 14-3-3 proteins: potential roles in vesicular transport and Ras signaling in Saccharomyces cerevisiae. Proc Natl Acad Sci U S A. 1995;92(25):11539-43.

14. van Heusden GP, Steensma HY. Yeast 14-3-3 proteins. Yeast. 2006;23(3):159-71.

15. Obsilová V, Silhan J, Boura E, Teisinger J, Obsil T. 14-3-3 proteins: a family of versatile molecular regulators. Physiol Res. 2008;57 Suppl 3:S11-21.

16. Obsil T, Obsilova V. Structural basis of 14-3-3 protein functions. Semin Cell Dev Biol. 2011;22(7):663-72.

17. Steinacker P, Aitken A, Otto M. 14-3-3 proteins in neurodegeneration. Semin Cell Dev Biol. 2011;22(7):696-704.

18. Ottmann C. Small-molecule modulators of 14-3-3 protein-protein interactions. Bioorg Med Chem. 2013;21(14):4058-62.

19. Andreotti PF, Monteiro da Silva JL, Bailão AM, Soares CM, Benard G, Soares CP, et al. Isolation and partial characterization of a $30 \mathrm{kDa}$ adhesin from Paracoccidioides brasiliensis. Microbes Infect. 2005;7(5-6):875-81.

20. Vallejo MC, Nakayasu ES, Matsuo AL, Sobreira TJ, Longo LV, Ganiko L, et al. Vesicle and vesicle-free extracellular proteome of Paracoccidioides brasiliensis: comparative analysis with other pathogenic fungi. J Proteome Res. 2012;11(3):1676-85.

21. da Silva JF, de Oliveira HC, Marcos CM, da Silva RA, da Costa TA, Calich VL, et al. Paracoccidoides brasiliensis $30 \mathrm{kDa}$ adhesin: identification as a 14-3-3 protein, cloning and subcellular localization in infection models. PLoS One. 2013;8(4):e62533.

22. de Oliveira HC, da Silva JF, Scorzoni L, Marcos CM, Rossi SA, de Paula e Silva ACA, et al. Importance of adhesins in virulence of Paracoccidioides spp. Front Microbiol. 2015;6:303.

23. da Silva JF, Vicentim J, de Oliveira HC, Marcos CM, Assato PA, et al. Influence of the Paracoccidioides brasiliensis 14-3-3 and gp43 proteins on the induction of apoptosis in A549 epithelial cells. Mem Inst Oswaldo Cruz. 2015;110(4):476-84.

24. van Heusden GP, Wenzel TJ, Lagendijk EL, de Steensma HY, van den Berg JA. Characterization of the yeast $\mathrm{BMH} 1$ gene encoding a putative protein homologous to mammalian protein kinase $\|$ activators and protein kinase C inhibitors. FEBS Lett. 1992;302(2):145-50.

25. Roberts RL, Mösch HU, Fink GR. 14-3-3 proteins are essential for RAS/MAPK cascade signaling during pseudohyphal development in S. cerevisiae. Cell. 1997;89(7):1055-65.

26. Bruckmann A, Steensma HY, Teixeira De Mattos MJ, Van Heusden GP. Regulation of transcription by Saccharomyces cerevisiae 14-3-3 proteins. Biochem J. 2004;382(Pt 3):867-75.

27. Zahrádka J, van Heusden GP, Sychrová H. Yeast 14-3-3 proteins participate in the regulation of cell cation homeostasis via interaction with Nha1 alkalimetal-cation/proton antiporter. Biochim Biophys Acta. 2012;1820(7):849-58.

28. Parua PK, Dombek KM, Young ET. Yeast 14-3-3 protein functions as a comodulator of transcription by inhibiting coactivator functions. J Biol Chem. 2014;289(51):35542-60.

29. Barr MM. Super models. Physiol Genomics. 2003;13(1):15-24.

30. Goffeau A, Barrell BG, Bussey H, Davis RW, Dujon B, Feldmann H, et al. Life with 6000 genes. Science. 1996;274(5287):546. 563-547.

31. van Heusden GP, van der Zanden AL, Ferl RJ, Steensma HY. Four Arabidopsis thaliana 14-3-3 protein isoforms can complement the lethal yeast bmh1 bmh2 double disruption. FEBS Lett. 1996;391(3):252-6.

32. Torres FA, Vilaça R, Pepe De Moraes LM, Reis VC, Felipe MS. Expression of a kexin-like gene from the human pathogenic fungus Paracoccidioides brasiliensis in Saccharomyces cerevisiae. Med Mycol. 2008;46(4):385-8.

33. Barreto L, Sorais F, Salazar V, San-Blas G, Niño-Vega GA. Expression of Paracoccidioides brasiliensis CHS3 in a Saccharomyces cerevisiae chs3 null mutant demonstrates its functionality as a chitin synthase gene. Yeast. 2010;27(5):293-300.

34. Paul S, Moye-Rowley WS. Functional analysis of an ATP-binding cassette transporter protein from Aspergillus fumigatus by heterologous expression in Saccharomyces cerevisiae. Fungal Genet Biol. 2013;57:85-91.

35. van Heusden GP, Griffiths DJ, Ford JC, Chin-A-Woeng TF, Schrader PA, Carr AM, et al. The 14-3-3 proteins encoded by the $\mathrm{BMH} 1$ and $\mathrm{BMH} 2$ genes are essential in the yeast Saccharomyces cerevisiae and can be replaced by a plant homologue. Eur J Biochem. 1995;229(1):45-53.
36. Kakiuchi K, Yamauchi Y, Taoka M, Iwago M, Fujita T, Ito T, et al. Proteomic analysis of in vivo 14-3-3 interactions in the yeast Saccharomyces cerevisiae. Biochemistry. 2007;46(26):7781-92.

37. Vicentini AP, Gesztesi JL, Franco MF, de Souza W, de Moraes JZ, Travassos LR, et al. Binding of Paracoccidioides brasiliensis to laminin through surface glycoprotein gp43 leads to enhancement of fungal pathogenesis. Infect Immun. 1994;62(4):1465-9.

38. Hanna SA, Monteiro da Silva JL, Giannini MJ. Adherence and intracellular parasitism of Paracoccidioides brasiliensis in Vero cells. Microbes Infect. 2000;2(8):877-84.

39. Torres I, Hernandez O, Tamayo D, Muñoz JF, Leitão NP, García AM, et al. Inhibition of PbGP43 expression may suggest that gp43 is a virulence factor in Paracoccidioides brasiliensis. PLoS One. 2013;8(7):e68434.

40. Gegembauer G, Araujo LM, Pereira EF, Rodrigues AM, Paniago AM, Hahn RC, et al. Serology of paracoccidioidomycosis due to Paracoccidioides lutzii. PLoS Negl Trop Dis. 2014;8(7):e2986.

41. Barbosa MS, Báo SN, Andreotti PF, de Faria FP, Felipe MS, dos Santos FL, et al. Glyceraldehyde-3-phosphate dehydrogenase of Paracoccidioides brasiliensis is a cell surface protein involved in fungal adhesion to extracellular matrix proteins and interaction with cells. Infect Immun. 2006;74(1):382-9.

42. Pereira LA, Báo SN, Barbosa MS, da Silva JL, Felipe MS, de Santana JM, et al. Analysis of the Paracoccidioides brasiliensis triosephosphate isomerase suggests the potential for adhesin function. FEMS Yeast Res. 2007;7(8):1381-8.

43. Donofrio FC, Calil AC, Miranda ET, Almeida AM, Benard G, Soares CP, et al. Enolase from Paracoccidioides brasiliensis: isolation and identification as a fibronectin-binding protein. J Med Microbiol. 2009;58(Pt 6):706-13.

44. Marcos CM, de Fátima da Silva J, de Oliveira HC, Moraes da Silva RA, Mendes-Giannini MJ, Fusco-Almeida AM. Surface-expressed enolase contributes to the adhesion of Paracoccidioides brasiliensis to host cells. FEMS Yeast Res. 2012;12(5):557-70.

45. da Silva Neto BR, de Fátima da Silva J, Mendes-Giannini MJ, Lenzi HL, de Almeida Soares CM, Pereira M. The malate synthase of Paracoccidioides brasiliensis is a linked surface protein that behaves as an anchorless adhesin. BMC Microbiol. 2009;9:272.

46. Dunn MF, Ramírez-Trujillo JA, Hernández-Lucas I. Major roles of isocitrate lyase and malate synthase in bacterial and fungal pathogenesis. Microbiology. 2009;155(Pt 10):3166-75.

47. de Oliveira KM, da Silva Neto BR, Parente JA, da Silva RA, Quintino GO, Voltan AR, et al. Intermolecular interactions of the malate synthase of Paracoccidioides spp. BMC Microbiol. 2013;13:107.

48. Brito WA, Rezende TC, Parente AF, Ricart CA, Sousa MV, Báo SN, et al. Identification, characterization and regulation studies of the aconitase of Paracoccidioides brasiliensis. Fungal Biol. 2011;115(8):697-707.

49. Marcos CM, de Oliveira HC, da Silva JF, Assato PA, Fusco-Almeida AM, Mendes-Giannini MJ. The multifaceted roles of metabolic enzymes in the Paracoccidioides species complex. Front Microbiol. 2014;5:719.

50. Fu H, Subramanian RR, Masters SC. 14-3-3 proteins: structure, function, and regulation. Annu Rev Pharmacol Toxicol. 2000;40:617-47.

51. Albuquerque P, Paes HC, Tavares AH, Fernandes L, Bocca AL, Silva-Pereira I, et al. Transcriptomics of the Host-Pathogen Interaction in Paracoccidioidomycosis. In: Passos GA, editor. Transcriptomics in Health and Disease. Springer International Publishing; 2014. p. 265-287.

52. Clapp C, Portt L, Khoury C, Sheibani S, Norman G, Ebner P, et al. 14-3-3 protects against stress-induced apoptosis. Cell Death Dis. 2012;3:e348.

53. Slubowski CJ, Paulissen SM, Huang LS. The GCKIII kinase Sps1 and the 14-33 isoforms, Bmh1 and Bmh2, cooperate to ensure proper sporulation in Saccharomyces cerevisiae. PLoS One. 2014;9(11):e113528.

54. Karkowska-Kuleta J, Kozik A. Moonlighting proteins as virulence factors of pathogenic fungi, parasitic protozoa and multicellular parasites. Mol Oral Microbiol. 2014;29(6):270-83.

55. Zhao J, Meyerkord CL, Du Y, Khuri FR, Fu H. 14-3-3 proteins as potential therapeutic targets. Semin Cell Dev Biol. 2011;22(7):705-12.

56. Stoeck K, Sanchez-Juan P, Gawinecka J, Green A, Ladogana A, Pocchiari M, et al. Cerebrospinal fluid biomarker supported diagnosis of CreutzfeldtJakob disease and rapid dementias: a longitudinal multicentre study over 10 years. Brain. 2012;135(Pt 10):3051-61.

57. Li Y, Liu L, Xiao Y, Zeng T, Zeng C. 14-3-30 is an independent prognostic biomarker for gastric cancer and is associated with apoptosis and proliferation in gastric cancer. Oncol Lett. 2015;9(1):290-4. 
58. Qureshi HY, Li T, MacDonald R, Cho CM, Leclerc N, Paudel HK. Interaction of 14-3-3zeta with microtubule-associated protein tau within Alzheimer's disease neurofibrillary tangles. Biochemistry. 2013;52(37):6445-55.

59. Jia B, Wu Y, Zhou Y. 14-3-3 and aggresome formation: implications in neurodegenerative diseases. In: Prion. vol. 8. United States; 2014.

60. Ko S, Kim JY, Jeong J, Lee JE, Yang WI, Jung WH. The role and regulatory mechanism of 14-3-3 sigma in human breast cancer. J Breast Cancer. 2014;17(3):207-18

61. Liu TA, Jan YJ, Ko BS, Liang SM, Chen SC, Wang J, et al. 14-3-3epsilon overexpression contributes to epithelial-mesenchymal transition of hepatocellular carcinoma. In: PLoS One. vol. 8. United States; 2013. e57968.

62. Cognetti D, Davis D, Sturtevant J. The Candida albicans 14-3-3 gene, BMH1, is essential for growth. Yeast. 2002;19(1):55-67.

63. Kelly MN, Johnston DA, Peel BA, Morgan TW, Palmer GE, Sturtevant JE. Bmh1p (14-3-3) mediates pathways associated with virulence in Candida albicans. Microbiology. 2009;155(Pt 5):1536-46.

64. Sáez-Rosón A, Sevilla MJ, Moragues MD. Identification of superficial Candida albicans germ tube antigens in a rabbit model of disseminated candidiasis. A proteomic approach. Int Microbiol. 2014;17(1):21-9.

65. Siles-Lucas MM, Gottstein B. The 14-3-3 protein: a key molecule in parasites as in other organisms. Trends Parasitol. 2003;19(12):575-81.

66. Inoue M, Nakamura Y, Yasuda K, Yasaka N, Hara T, Schnaufer A, et al. The 14-3-3 proteins of Trypanosoma brucei function in motility, cytokinesis, and cell cycle. J Biol Chem. 2005;280(14):14085-96.

67. Inoue M, Yasuda K, Uemura H, Yasaka N, Schnaufer A, Yano M, et al. Trypanosoma brucei 14-3-3I and II proteins predominantly form a heterodimer structure that acts as a potent cell cycle regulator in vivo. J Biochem. 2013;153(5):431-9.

68. Assossou O, Besson F, Rouault JP, Persat F, Ferrandiz J, Mayençon M, et al. Characterization of an excreted/secreted antigen form of 14-3-3 protein in Toxoplasma gondii tachyzoites. FEMS Microbiol Lett. 2004;234(1):19-25.

69. Meng M, He S, Zhao G, Bai Y, Zhou H, Cong H, et al. Evaluation of protective immune responses induced by DNA vaccines encoding Toxoplasma gondii surface antigen 1 (SAG1) and 14-3-3 protein in BALB/C mice. Parasit Vectors. 2012;5:273.

70. Siles-Lucas M, Merli M, Mackenstedt U, Gottstein B. The Echinococcus multilocularis 14-3-3 protein protects mice against primary but not secondary alveolar echinococcosis. Vaccine. 2003;21(5-6):431-9.

71. Andrade MA, Siles-Lucas M, Espinoza E, Pérez Arellano JL, Gottstein B, Muro A. Echinococcus multilocularis laminated-layer components and the E14t 14-3-3 recombinant protein decrease NO production by activated rat macrophages in vitro. Nitric Oxide. 2004;10(3):150-5.

72. Siles-Lucas M, Merli M, Gottstein B. 14-3-3 proteins in Echinococcus: their role and potential as protective antigens. Exp Parasitol. 2008;119(4):516-23.

73. Teichmann A, Vargas DM, Monteiro KM, Meneghetti BV, Dutra CS, Paredes R, et al. Characterization of 14-3-3 isoforms expressed in the Echinococcus granulosus pathogenic larval stage. J Proteome Res. 2015;14(4):1700-15.

74. Schechtman D, Tarrab-Hazdai R, Arnon R. The 14-3-3 protein as a vaccine candidate against schistosomiasis. Parasite Immunol. 2001;23(4):213-7.

75. Siles-Lucas M, Uribe N, López-Abán J, Vicente B, Orfao A, Nogal-Ruiz JJ, et al. The Schistosoma bovis Sb14-3-3zeta recombinant protein cross-protects against Schistosoma mansoni in BALB/c mice. Vaccine. 2007;25(41):7217-23.

76. El Ridi R, Tallima H. Schistosoma mansoni ex vivo lung-stage larvae excretory-secretory antigens as vaccine candidates against schistosomiasis. Vaccine. 2009;27(5):666-73.

77. Qian CY, Huang B, Yu CX, Zhang J, Yin XR, Wang J, et al. Detection of the circulating antigen 14-3-3 protein of Schistosoma japonicum by timeresolved fluoroimmunoassay in rabbits. Parasit Vectors. 2011:4:95.

78. Yu Q, Yang H, Guan F, Feng Y, Yang X, Zhu Y. Detection of IgG in sera of patients with schistosomiasis japonica by developing magnetic affinity enzyme-linked immunoassay based on recombinant 14-3-3 protein. Trans $R$ Soc Trop Med Hyg. 2014;108(1):37-41.

79. Kraus PR, Hofmann AF, Harris SD. Characterization of the Aspergillus nidulans 14-3-3 homologue, ArtA. FEMS Microbiol Lett. 2002;210(1):61-6.

80. Pasko MT, Piscitelli SC, Van Slooten AD. Fluconazole: a new triazole antifungal agent. Dicp. 1990;24(9):860-7.

81. Klug L, Daum G. Yeast lipid metabolism at a glance. FEMS Yeast Res. 2014;14(3):369-88.

82. da Silva Neto BR, Carvalho PF, Bailão AM, Martins WS, Soares CM, Pereira M Transcriptional profile of Paracoccidioides spp. in response to itraconazole. BMC Genomics. 2014;15:254.
83. Klemptner RL, Sherwood JS, Tugizimana F, Dubery IA, Piater LA. Ergosterol, an orphan fungal microbe-associated molecular pattern (MAMP). Mol Plant Pathol. 2014;15(7):747-61.

84. Nes WD, Zhou W, Ganapathy K, Liu J, Vatsyayan R, Chamala S, et al. Sterol 24-C-methyltransferase: an enzymatic target for the disruption of ergosterol biosynthesis and homeostasis in Cryptococcus neoformans. Arch Biochem Biophys. 2009;481(2):210-8

85. Brilhante RS, Caetano EP, Lima RA, Castelo Branco DS, Serpa R, Oliveira JS, et al. In vitro antifungal activity of miltefosine and levamisole: their impact on ergosterol biosynthesis and cell permeability of dimorphic fungi. J Appl Microbiol. 2015;119(4):962-9.

86. Keller P, Müller C, Engelhardt I, Hiller E, Lemuth $\mathrm{K}$, Eickhoff H, et al. An antifungal benzimidazole derivative inhibits ergosterol biosynthesis and reveals novel sterols. Antimicrob Agents Chemother. 2015;59(10):6296-307.

87. Shikanai-Yasuda MA, Telles Filho FQ, Mendes RP, Colombo AL, Moretti ML. Guidelines in paracoccidioidomycosis. Rev Soc Bras Med Trop. 2006;39(3):297-310.

88. Bocca AL, Amaral AC, Teixeira MM, Sato PK, Sato P, Shikanai-Yasuda MA, et al. Paracoccidioidomycosis: eco-epidemiology, taxonomy and clinical and therapeutic issues. Future Microbiol. 2013;8(9):1177-91.

89. Ellis D. Amphotericin B: spectrum and resistance. J Antimicrob Chemother. 2002:49 Suppl 1:7-10.

90. Ghannoum MA, Rice LB. Antifungal agents: mode of action, mechanisms of resistance, and correlation of these mechanisms with bacterial resistance. Clin Microbiol Rev. 1999;12(4):501-17.

91. Sheehan DJ, Hitchcock CA, Sibley CM. Current and emerging azole antifungal agents. Clin Microbiol Rev. 1999;12(1):40-79.

92. Baddley JW, Moser SA. Emerging fungal resistance. Clin Lab Med. 2004;24(3):721-35. vii.

93. Sionov $\mathrm{E}$, Lee H, Chang YC, Kwon-Chung KJ. Cryptococcus neoformans overcomes stress of azole drugs by formation of disomy in specific multiple chromosomes. PLoS Pathog. 2010;6(4):e1000848.

94. Noël T. The cellular and molecular defense mechanisms of the Candida yeasts against azole antifungal drugs. J Mycol Med. 2012;22(2):173-8.

95. Mo C, Bard M. Erg28p is a key protein in the yeast sterol biosynthetic enzyme complex. J Lipid Res. 2005;46(9):1991-8.

96. Schulz TA, Prinz WA. Sterol transport in yeast and the oxysterol binding protein homologue (OSH) family. Biochim Biophys Acta. 2007;1771(6):769-80.

97. Jiang B, Brown JL, Sheraton J, Fortin N, Bussey $H$. A new family of yeast genes implicated in ergosterol synthesis is related to the human oxysterol binding protein. Yeast. 1994;10(3):341-53.

98. Hanna M, Xiao W. Isolation of nucleic acids. Methods Mol Biol. 2006:313:15-20.

99. Yuan J, Ching CB. Dynamic control of ERG9 expression for improved amorpha-4,11-diene production in Saccharomyces cerevisiae. Microb Cell Fact. 2015;14:38.

100. Younes SS, Khalaf RA. The Candida albicans Hwp2p can complement the lack of filamentation of a Saccharomyces cerevisiae flo11 null strain. Microbiology. 2013;159(Pt 6):1160-4

\section{Submit your next manuscript to BioMed Central and take full advantage of:}

- Convenient online submission

- Thorough peer review

- No space constraints or color figure charges

- Immediate publication on acceptance

- Inclusion in PubMed, CAS, Scopus and Google Scholar

- Research which is freely available for redistribution 